\title{
Commitment Versus Discretion in Climate and Energy Policy
}

\author{
Florian Habermacher ${ }^{1,2,3} \cdot$ Paul Lehmann ${ }^{4,5}$
}

Accepted: 19 March 2020 / Published online: 2 April 2020

(c) The Author(s) 2020

\begin{abstract}
To decarbonize the power sector, policy-makers need to commit to long-term credible rules for climate and energy policy. Otherwise, risk of opportunistic policy-making will impair investments into low-carbon technologies. However, the future benefits and costs of decarbonization are subject to substantial uncertainties. Thus, there may also be societal gains from allowing policy-makers the discretion to adjust the policies as new information becomes available. We examine how this trade-off between policy commitment-either unconditional or state-contingent - and discretion affects the optimal intertemporal design of market-based instruments in the power sector. Using a dynamic partial equilibrium model, we show that commitment to a state-contingent level of ambition for the marketbased instrument leads to higher welfare than both unconditional commitment and discretion. With benefit uncertainty, the choice between the practically more feasible approaches of unconditional commitment and discretion is analytically ambiguous. A basic numerical illustration suggests that policy discretion may outperform unconditional commitment in terms of welfare. However, this result is reversed when only a limited fraction of benefit uncertainty resolves in reasonable time, when future policy-makers have own agendas, or when investors are risk-averse. With cost uncertainty, policy discretion is welfare-superior if the government can commit to a technology deployment target.
\end{abstract}

Keywords Climate change $\cdot$ Public policy $\cdot$ Subsidies $\cdot$ Renewable energy $\cdot$ Uncertainty Commitment $\cdot$ Hold-up

JEL Classification $\mathrm{H} 23 \cdot \mathrm{Q} 42 \cdot \mathrm{Q} 48 \cdot \mathrm{Q} 54 \cdot \mathrm{Q} 58$

Paul Lehmann

lehmann@wifa.uni-leipzig.de

Florian Habermacher

florian.habermacher@unisg.ch

1 Swiss Institute for International Economics and Applied Economic Research, University of St. Gallen, St. Gallen, Switzerland

2 Institute for New Economic Thinking, University of Oxford, Oxford, UK

3 Aurora Energy Research, Oxford, UK

4 Faculty of Economics and Management Science, University of Leipzig, Ritterstr. 12, 04103 Leipzig, Germany

5 Department of Economics, Helmholtz Centre for Environmental Research - UFZ, Leipzig, Germany 


\section{Introduction}

It is a long-standing paradigm that economic policy should commit to long-term credible rules for private economic activities to promote economic development. Kydland and Prescott (1977) already emphasized in their seminal paper that the discretion to adjust a policy over time would reduce welfare because it would distort the decisions of forwardlooking rational agents at present. However, it has subsequently been emphasized that discretion may also generate economic benefits if policies can be adjusted over time to better reflect initially uncertain future policy costs and benefits, for example in the presence of unforeseen events and shocks (Fisher 1977; Lohmann 1992; Rogoff 1985). Hence, there is a fundamental trade-off between policy commitment and discretion. In this paper, we analyze this trade-off and its implications for optimal decision-making in climate policy. In particular, we shed light on implications for market-based instruments for decarbonization in the power sector.

Market-based instruments to reduce $\mathrm{CO}_{2}$ emissions in the power sector may take different forms. First-best approaches price $\mathrm{CO}_{2}$ emissions directly through carbon taxes or carbon trading schemes. Second-best approaches include subsidies for low-carbon power generation technologies, most notably renewable energy sources (RES) (e.g., Kalkuhl et al. 2013; Palmer and Burtraw 2005). Both approaches are widely applied throughout the world, and often combined (REN21 2016; World Bank 2017). Strikingly, existing market-based approaches have followed quite diverse pathways of commitment and discretion. On the one hand, prominent examples like the European Union's Emissions Trading Scheme (EU ETS) have exhibited moderate degrees of commitment. The EU ETS foresees an explicit long-term trajectory for its carbon cap, with a pre-defined annual reduction of issued allowances by $1.74 \%$ until 2020, and 2.2\% thereafter (European Commission 2014). ${ }^{1}$ On the other hand, Australia exerted a maximum degree of discretion when it abolished its carbon tax in 2014, just two years after introduction (World Bank 2017). High degrees of discretion have been even more common for RES support schemes. For example, the German feed-in tariff has seen constant adjustments (e.g., Hoppmann et al. 2014; Strunz et al. 2016). Spain constituted an extreme example when it adopted a moratorium on RES support in 2012 (Del Rio and Mir-Artigues 2014). While changes in the best cases only affect new installations (including those already in the process of project preparation), retrospective changes of policy rules for existing RES plants have also been quite frequent in several EU Member States (Fouquet and Nysten 2015). It is unclear to what extent the observed levels of commitment and discretion are welfare-improving or -decreasing, as there may be important trade-offs between commitment and discretion for climate policy.

Why is the choice between commitment and discretion ambiguous for climate policy? On the one hand, discretion may open up for opportunistic adjustments to climate policy if the policy announced ex ante is not time-consistent. Policy-makers introduce marketbased policies to promote investments into research and development, manufacturing, and deployment of low-carbon technologies, and to generate the corresponding benefits of mitigating climate change. Many of these investments are large-scale, long-lived and largely irreversible_-as for most energy-related investments (Neuhoff 2005). Once the investments have been locked in, policy-makers can have an incentive to reduce the ambition of climate

\footnotetext{
1 Certainly, allowance prices in the EU ETS have been extremely volatile-despite the long-term commitment in terms of the emissions cap trajectory_for a variety of reasons (see, e.g., Hintermann et al. 2016).
} 
policy. Reasons include societal costs (e.g., deadweight losses, administrative costs of market-based policies), distributional concerns (e.g., higher power prices due to market-based policies $),{ }^{2}$ or simply politico-economic attempts to cater for vested interests. For example, unexpectedly high power price increases have been the major driver behind the discretion in RES policy, as observed in Germany and Spain (Del Rio and Mir-Artigues 2014; Strunz et al. 2016). The anticipation of possible future policy adjustments can lead to suboptimal investment decisions of private actors today: Firms foreseeing lower or uncertain levels of political ambition in the future will have an incentive to reduce investments into research, development, and deployment of low-carbon technologies. This is referred to as the holdup problem (Garnier and Madlener 2016; Nemet et al. 2017; Schleich et al. 2017). In this respect, a high degree of discretion may be viewed critically. A lacking commitment to a long-term climate policy path disincentivizes investments. Thereby, it may impair the decarbonization of the power sector and the attainment of ambitious emission reduction targets.

On the other hand, the future benefits and costs of climate policies are equally subject to large uncertainties. These uncertainties imply that the level of ambition chosen ex ante may turn out to be inefficiently low or high ex post, when compared to actual costs and benefits at a future time. Therefore, welfare may be increased if policy makers have the discretion to adjust climate policy as new knowledge becomes available-which has been pointed out for industry policy in general (Rodrik 2014) and climate and energy policy in particular (Aghion et al. 2009; Foxon and Pearson 2008; Nemet et al. 2017). First, important uncertainties are related to the social cost of carbon (Greenstone et al. 2013; Tol 2009). Second, the future development of costs of low-carbon technologies is similarly uncertain. This is, inter alia, due to large variations in observed learning rates (Rubin et al. 2015), and the impossibility to predict technological breakthroughs. Thus, the potential trade-off between commitment and discretion is a highly relevant issue for the optimal design of marketbased instruments for climate policy. ${ }^{3}$

Our study addresses the following question: under which conditions should climate policy commitment or discretion be preferred to efficiently promote the investments needed to reduce $\mathrm{CO}_{2}$ emissions? To analyze the trade-off between commitment and discretion, we develop a stylized dynamic partial equilibrium model for the power sector. Within this framework, we examine investments in low-carbon technologies for power generation, such as RES, under three climate policy scenarios. The scenarios vary in the assumptions regarding when and how the policy-maker decides on the future level of ambition for a market-based instrument:

1. Rule-based commitment the policy-maker can commit to a set of state-contingent levels of ambition for the market-based instrument and explicitly relate it to possible future states of the world (e.g., high and low benefits or costs). Its perfect implementation requires contracting all contingencies relevant for the future design of climate policy.

\footnotetext{
2 One could see the UK's carbon price freeze from 2016 to 2019 (HM Revenue \& Customs 2014) as well as the UK Labour party's promise for an electricity price freeze during the 2013 election as examples of this type, viable in the short run as investments for infrastructure for (clean) electricity production could not be undone.

3 Brunner et al. (2012), Finon and Perez (2007), Hepburn (2006), Nemet et al. (2017) and Purkus et al. (2015) highlight this trade-off for RES support schemes. However, they do not carry out a formal or empirical analysis.
} 
We will argue that this can be achieved only very imperfectly in practice, so this scenario mostly serves as a benchmark for the outcome of the other scenarios.

2. Unconditional commitment the policy-maker defines the long-run level of ambition of the market-based instrument today and can commit to not adjusting it in the future, even if knowledge gained in the future suggests it is inefficient. This scenario represents one extreme case. It minimizes the hold-up problem and the cost of political opportunism. Yet, it foregoes potential benefits from adjusting policy to new information in the future.

3. Discretion the level of ambition of the market-based instrument can be freely adapted in the future. It may differ from the level in the previous policy scenarios because of both opportunistic policy-making and new knowledge on costs or benefits. This scenario represents the second extreme case. It allows reaping welfare gains if new knowledge can be incorporated into policy design. However, is also opens up for hold-up problems and political opportunism.

We find that rule-based commitment generally outperforms both unconditional commitment and discretion. Yet, perfect rule-based commitment itself seems in many cases impractical, given difficulties to contractually specify and monitor possible states of the world. Consequently, the comparison of unconditional commitment and discretion is more relevant in practice. The choice between the two approaches is analytically ambiguous. A numerical application for plausible ranges of the social cost of carbon avoided provides additional insight. In a basic version of the framework, discretion, in the sense of an optimal, forward-looking adaptation of policies to new information, seems superior to unconditional commitment for reasonable parameter values, even if only marginally so. The relative advantage of discretion vanishes once we account for (a) climate uncertainty resolving only partially over time, (b) uncertainty due to non-benevolent policy-makers deviating from inter-temporally optimal policy levels, and (c) risk-averse investors. We also reflect briefly on how the policy choice is affected by uncertainty of the future costs of low-carbon technologies (instead of external benefits). In this case, commitment is strictly superior (inferior) to discretion if the market-based instrument is meant to internalize an external damage (to attain a politically set technology deployment target). Overall, our results therefore suggest that, while pertinent economic reasons for discretionary climate policy-making exist, the second-best policy approach is still in many cases to commit to a longer-term climate policy path.

The optimal choice between commitment and discretion in environmental policy has already received some attention. A prominent strand in the debate assumes that a single firm with market power foresees that its investment decision today will affect the stringency of future environmental policy. Consequently, it adapts investment strategically (the ratchet effect). In the simplest setting, commitment is then strictly superior to discretion (Biglaiser et al. 1995; Downing and White 1986; Yao 1988). Yet, the choice between commitment and discretion may become ambiguous if the ratchet effect combines with additional policy constraints, e.g., if the convexity of environmental damages is not considered in tax design (Amacher and Malik 2002), or if positive externalities related to research and development cannot be addressed by specific subsidies but only indirectly through the emissions policy (Laffont and Tirole 1996; Requate 2005). Laffont and Tirole as well as Requate also show that rule-based commitment-e.g., in the form of option allowances or a tax menustrictly outperforms unconditional commitment and full discretion.

Requate and Unold $(2001,2003)$ show that discretion can be advantageous in the presence of uncertainty of environmental benefits to enable policy learning (cf. also D'Amato 
and Dijkstra 2015; Karp and Zhang 2005; Krysiak 2011). Yet, these studies do not account for the ratchet effect. Malik (1991) and Tarui and Polasky (2005) combine benefit uncertainty and strategic firm behavior. They show that under these assumptions, the choice between policy discretion and commitment becomes ambiguous. Kennedy (1999) and Jakob and Brunner (2014) highlight that in this case, rule-based commitment is again superior to both unconditional commitment and discretion.

Our paper is similar to these studies in the way we consider uncertainty, and thus the benefits of discretion. However, it is fundamentally different in the way we model the cost of discretion. We abstain from assuming a ratchet effect and strategic firm behavior. In a world where a market-based instrument is imposed on numerous firms, it may not be plausible to assume that decisions of a single firm can significantly affect the level of ambition of this policy in the future. Instead, we consider that discretion produces additional costs because it opens up for opportunistic policy-making. Several studies point out that this is a concern if policy-makers consider additional policy objectives besides pollution control, such as distributional or public finance concerns. They discuss how this problem can be reduced by different means of commitment, such as appropriately choosing between price and quantity approaches (Baldursson and von der Fehr 2008; May and Chiappinelli 2018), by earmarking tax revenues (Marsiliani and Renström 2000), by combining carbon pricing with complementary technology policies (Abrego and Perroni 2002; Ulph and Ulph 2013), by introducing supra-nationally set policy targets (May and Chiappinelli 2018), or by delegating climate policy-making to an independent carbon bank (Helm et al. 2003, 2004). However, these studies largely ignore the potential benefits of discretion if costs and benefits of environmental policy are uncertain. Consequently, they assume that full commitment to an intertemporal environmental policy path would always be the optimal solution. Our paper adds to this literature by considering how the choice between commitment and discretion becomes ambiguous if uncertainty is added.

The remainder of the paper is organized as follows. Section 2 introduces the stylized dynamic partial equilibrium model for the power sector. Section 3 provides the basic analytical discussion and numerical illustration of the choice between climate policy commitment and discretion when benefits are uncertain. Section 4 relaxes some of the assumptions made for the basic model to capture additional aspects of reality. Section 5 briefly discusses the implications of uncertain technology costs. Section 6 provides a discussion of our analytical and numerical results, and Sect. 7 concludes.

\section{Model}

To analyze the trade-off between commitment and discretion, we develop a dynamic partial equilibrium model of the power sector. For this purpose, we use the simplest suitable approach to analyze how commitment and discretion in climate policy affects investments into a low-carbon technology for power generation. Where appropriate, we illustrate our assumptions and argumentation by referring to the specific case of RES technologies, the currently most prominent low-carbon generation technology. To keep our model results traceable, we do not explicitly model possible impacts on investments into other, carbonintensive generation technologies. We assume that a representative firm with rational expectations can invest into power plants in two periods $t=\{1,2\}$, using a low-carbon technology with capacity $x_{t}$ for power generation. Plants installed are in operation for two periods. We include a third period to generate symmetric pay-off streams for investments 
made in the first and second period. Since we are primarily interested in understanding inter-temporal investment decisions taken in periods 1 and 2, and to avoid complicating our analysis with little benefit, we simplify period 3 by leaving most parameters equal to period 2 's. Future benefits and costs are discounted at factor $\delta$. For simplicity, we assume that the conversion factor from capacity to power is constant, and we normalize it to unity, i.e., power generation corresponds to available capacity in that period. Consequently, periodspecific total power generation $q_{t}$ from the low-carbon technology is given as:

$$
q_{1}=x_{1} \quad q_{2}=x_{1}+x_{2} \quad q_{3}=x_{2}
$$

The power market is assumed to clear, and for simplicity consumer benefit increases linearly in power generation (or consumption):

$$
V_{t}\left(q_{t}\right)=v q_{t}
$$

Correspondingly, the wholesale market price for power is constant and given by ${ }^{4}$ :

$$
p_{t}=v
$$

Generation costs of the low-carbon technology are assumed to be limited to sunk, convex investment costs, as holds approximately true for non-thermal RES:

$$
C_{t}\left(x_{t}\right)=\frac{c_{t}}{2} x_{t}^{2}
$$

Convexity represents the fact that some inputs for deploying the low-carbon technology — such as windy (or sunny) and politically accepted deployment sites for RES plants, trained labor, investment capital, or construction material-become scarcer as more plants are installed in a single period, i.e., the technology supply curve is upward-sloping for a given period (see, e.g., Denholm and Margolis 2008; Kline et al. 2008). Moreover, convexity in costs can also be seen as a proxy for the fact that the market value of power generated with low-carbon technologies may be falling with higher penetration rates (e.g., Hirth 2013). Absence of variable generation costs implies that power from investments made in period 1 (or 2) can be generated in period 2 (or 3) at zero cost. This creates a path-dependency for generation in period $t+1$ based on sunk investment in period $t$. Throughout most of our paper we assume that the cost parameter $c_{t}$ is known with certainty. We discuss implications of relaxing this assumption in Sect. 5.

We assume that power generation from the low-carbon technology produces an external benefit $B_{t}\left(q_{t}\right)$, e.g., in terms of avoided social cost of carbon, with

$$
B_{t}\left(q_{t}\right)=b_{t} q_{t}
$$

The benefit parameter $b_{t}$ may vary between period 1 and 2 (but is identical in periods 2 and 3). Benefits generated in one period are independent of those in previous periods. Hence, we ignore the implications of stock pollutants. This may be reasonable as long as the country and/or sector we look at is sufficiently small. At the beginning of period 1 , the benefit parameter for period 1 is known. The parameter for period 2 (and 3) may be

\footnotetext{
4 An alternative, compatible interpretation is that consumers have decreasing marginal utility from power consumption and that power from low-carbon technologies is an alternative to conventional power which has constant returns to scale at unitary $\cos t$.
} 
uncertain at this point and depend on the future state $i \in\{H, L\}$ : it is $b_{2 H}$ in a high-benefit state $H$ occurring with probability $\alpha$, and $b_{2 L}$ in a low-benefit state occurring with probability $(1-\alpha)$. Correspondingly, the expectation value $E\left[b_{2}\right]$ and the variance $\sigma_{b}^{2}$ are:

$$
\begin{aligned}
E\left[b_{2}\right] & =\alpha b_{2 H}+(1-\alpha) b_{2 L} \\
\sigma_{b}^{2} & =\left(b_{2 H}-b_{2 L}\right)^{2} \alpha(1-\alpha)
\end{aligned}
$$

In the presence of uncertainty, the benefit function for periods 2 and 3 can therefore be rewritten as $B_{t i}\left(q_{t}\right)=b_{2 i} q_{t}$. Uncertainty of the actual state of the benefit is assumed to vanish at the beginning of period 2 as more information becomes available. In Sect. 4, we reconsider this strong assumption, assuming that only a part of climate uncertainty may resolve within a decade.

To internalize the external benefit, the policy-maker introduces a market-based instrument. No matter whether this instrument is set up as a carbon price (carbon tax or emissions trading scheme) or a direct subsidy to low-carbon technology (e.g., feed-in tariff or quota with tradable green certificates for RES generation), it eventually results in a comparative cost advantage for the low-carbon technology. To keep things simple, we will refer to this cost advantage as a (implicit) subsidy $s_{t}$, paid per unit of electricity generated in all periods. The subsidy may vary between period 1 and 2 (but remains unchanged between 2 and 3, i.e., $s_{2}$ applies in period 3 as well). The subsidy also brings about policy costs $L_{t}\left(s_{t}, q_{t}\right)$ whose level we simplify to be proportional to the subsidy volume,

$$
L_{t}\left(s_{t}, q_{t}\right)=l s_{t} q_{t}
$$

These policy costs may represent any type of social overhead costs related to implementing the market-based instrument that is not otherwise covered by our model (i.e., beyond policy-induced changes in investment costs, and the more directly energy-related consumer and producer surplus). For any type of climate and energy policy, relevant costs may include adverse (general equilibrium) effects outside the power sector, disutility related to adverse distributional impacts, or transaction costs of administering the market-based instrument. For direct subsidies to low-carbon technologies, additional costs may be related to the marginal welfare cost of taxes levied to fund the subsidy, or to the excess burden on power consumers arising if the subsidy is funded by a surcharge on the power price. ${ }^{5}$ A linear renewables policy cost seems a reasonable approximation since RES investments and related public expenditures account only for a minor share in the size of the economy or of overall government expenditures and levies. ${ }^{6}$

When deciding on the subsidy rate, the policy-maker maximizes the sum of the presentdiscounted private and external consumption benefits, net of investment and policy costs. On the one hand, the policy maker thus aims to stimulate investment by internalizing the external benefit. On the other hand, she tries to restrict the related policy costs. This will be the decisive trade-off playing out in the subsequent policy analyses. As long as the policy $\operatorname{costs} L_{t}$ are assumed to be true social costs, the calculus of the policy-maker corresponds to that of a social planer maximizing social welfare. But without commitment, the game is not

\footnotetext{
5 In our simple partial equilibrium model with only low-carbon power generation, the surcharge on the power price to fund the subsidy would be equal to $s_{t}$.

6 Introducing convex policy costs makes results less tractable, without altering main results qualitatively. It adds, though, to the ambiguity we find later between unconditional commitment and discretion.
} 
subgame-perfect, opening up for opportunistic policy-making: with investment $x_{1}$ already locked in (sunk capital), period-2 subsidy $s_{2}$ can ex-post be set at a low level without affecting the value of period-1 investment $x_{1}$ whose value had been set as a function of the exante expectation for the new subsidy, $E\left[s_{2}\right]$. Absent any commitment, subsidy $s_{2}$ will thus be set with only the effect on $x_{2}$ in mind, while its (anticipated) value also affects $x_{1}$.

We consequently analyze three sets of policy scenarios which vary in when and how the policy-maker can decide on the subsidy applicable for periods 2 and 3 for both existing and new investments (cf. introduction):

- Rule-based commitment $(R)$ : In period 1, the policy-maker can commit to a state-contingent subsidy rule, setting for each state $i$ a corresponding subsidy rate $s_{2 i}$, adapted to the benefit $b_{2 i}$.

- Unconditional commitment $(C)$ : In period 1, the policy-maker can commit to a fixed subsidy rate $s_{2}$ paid in period 2 .

- Discretion $(D)$ : In period 1, the policy-maker cannot make any commitment. She decides on a subsidy rate $s_{2 i}$ only in period 2 .

An additional policy option could be to discriminate between existing (period-1) and new (period-2) investments for policy adjustments in period 2-as it is often applied for RES subsidies. In this case, the policy-maker would be assumed to commit to a fixed subsidy rate for period-1 investments over all periods (as with unconditional commitment). Subsidy adjustments to account for new information on external benefits would only be allowed to apply to new investments in period 2. We do not model this case separately because it is analytically almost identical to rule-based commitment. Furthermore, such a discriminatory approach is usually ruled out for carbon prices (recall that the subsidy can be understood as the comparative advantage created for low-carbon investments by a carbon price). Carbon prices are typically designed with levels changing over time, but less varying across sectors and even less so across age classes of infrastructure. Finally, even though a discriminatory approach is often applied to direct subsidies for low-carbon technologies, e.g., for RES feed-in tariffs, it can only partly solve the fundamental issue of time-inconsistency in practice. Among others, this is because large RES investment projects typically take several years to develop. Consequently, a significant share of investment costs is bound well ahead of the actual commissioning of a plant. In contrast, the eventually applicable subsidy rate is often fixed legally once the RES plant goes online. Thus, there is always a need to choose between unconditional commitment, rule-based commitment and discretion, even if subsidy adjustments discriminate between existing and new investments.

Our subsequent analysis of optimal RES policy-making with uncertain external benefits distinguishes a basic setting with simple assumptions about the world (Sect. 3) from three more realistic settings (Sect. 4) assuming that (a) uncertainty dissolves only partially over time, (b) future policy decision is uncertain, e.g., due to non-benevolent policy-making, or (c) investors are risk averse.

\section{Uncertain External Benefits: Basic Approach}

We now turn to analyzing our three policy scenarios in the presence of uncertain external benefits from the low-carbon technology investments. First, we examine policy choices in a basic setting, assuming that (a) uncertainty dissolves completely at the beginning of 
period 2, (b) today's policy-makers and firms can perfectly foresee future policy-makers' responses to different states of the world, and (c) firms are risk-neutral. We then relax these assumptions in Sect. 4. We complement both steps of analysis by numerical illustrations.

\subsection{Analytical Approach}

In the following, we study and compare rule-based commitment, unconditional commitment, and discretion analytically.

\subsubsection{Rule-Based Commitment (R) Versus Unconditional Commitment (C)}

Let us first compare rule-based to unconditional commitment. For rule-based commitment (denoted by superscript $R$ ), we assume the policy-maker can commit, in period 1, to implementing a state-contingent period-2 subsidy, which depends on the eventual benefit parameter observed at the beginning of period 2 .

The representative firm's optimization problem is to choose investment levels $x_{1}$ and $x_{2}$ to maximize expected profit $\pi$ over all periods:

$$
\max _{x_{1}, x_{2 i}} \pi^{R}=p_{1} q_{1}-C_{1}\left(x_{1}\right)+s_{1} q_{1}+E_{i}\left[\delta\left(p_{2} q_{2 i}-C_{2}\left(x_{2 i}\right)+s_{2 i} q_{2 i}\right)+\delta^{2}\left(p_{3} q_{3 i}+s_{2 i} q_{3 i}\right)\right]
$$

The firm considers the subsidies as well as the corresponding investment and generation levels separately for the high- and low-subsidy state, weighted by the corresponding probabilities. The policy-maker aims to maximize the expectation value of social welfare for rule-based commitment, which is:

$$
\begin{aligned}
\max _{s_{1}, s_{2 i}} W^{R}= & V_{1}\left(q_{1}\right)-C_{1}\left(x_{1}\right)-L_{1}\left(s_{1}, q_{1}\right)+B_{1}\left(q_{1}\right) \\
& +E_{i}\left[\delta\left(\left(V_{2}\left(q_{2 i}\right)-C_{2}\left(x_{2 i}\right)-L_{2}\left(s_{2 i}, q_{2 i}\right)+B_{2 i}\left(q_{2 i}\right)\right)\right)\right. \\
& \left.+\delta^{2}\left(\left(V_{3}\left(q_{3 i}\right)-L_{3}\left(s_{2 i}, q_{3 i}\right)+B_{3 i}\left(q_{3 i}\right)\right)\right)\right]
\end{aligned}
$$

For unconditional commitment (denoted by superscript $C$ ), we assume the policy maker can commit, in period 1 , to a single, unconditional period- 2 subsidy rate. Consequently, the firm's objective simplifies to

$$
\max _{x_{1}, x_{2}} \pi^{C}=p_{1} q_{1}-C_{1}\left(x_{1}\right)+s_{1} q_{1}+\delta\left(p_{2} q_{2}-C_{2}\left(x_{2}\right)+s_{2} q_{2}\right)+\delta^{2}\left(p_{3} q_{3}+s_{2} q_{3}\right)
$$

The corresponding optimization problem of the policy-maker is:

$$
\begin{aligned}
\max _{s_{1}, s_{2}} W^{C}= & V_{1}\left(q_{1}\right)-C_{1}\left(x_{1}\right)-L_{1}\left(s_{1}, q_{1}\right)+B_{1}\left(q_{1}\right)+E_{i}\left[\delta\left(V_{2}\left(q_{2}\right)-C_{2}\left(x_{2}\right)-L_{2}\left(s_{2}, q_{2}\right)+B_{2 i}\left(q_{2}\right)\right)\right. \\
& \left.+\delta^{2}\left(V_{3}\left(q_{3}\right)-L_{3}\left(s_{2}, q_{3}\right)+B_{3 i}\left(q_{3}\right)\right)\right]
\end{aligned}
$$

For both policy scenarios, the optimization problems of the policy-maker can be solved by backward induction (see Appendix "Rule-Based Commitment Versus Unconditional Commitment"). The resulting welfare levels compare as follows: 


$$
W^{R *}-W^{C *}=\frac{\sigma_{b}^{2} \delta(1+\delta)^{2}}{2 c_{2}(1+2 l)}
$$

Equation (5) illustrates that welfare under unconditional commitment is strictly lower than under rule-based commitment. This is due to the fact that with unconditional commitment, society fails to benefit from adjusting to the actual period- 2 climate cost. This loss increases with a higher variance in future benefits $\sigma_{b}^{2}$ and a lower discount rate (implying a higher discount factor $\delta$ ), both of which increase the (present) relative benefit of having a rule-based policy adjustment. The loss decreases in marginal investment $\operatorname{costs} c_{2}$ and marginal policy costs $l$. Increases in both variables lead to lower optimal investment levels in period 2 in both policy scenarios, reducing also the scope for suboptimal investments due to unconditional commitment.

\subsubsection{Rule-Based Commitment (R) Versus Discretion (D)}

We now turn to comparing rule-based commitment to discretion. Under policy-making with discretion (denoted by superscript $D$ ), the optimization problems of the firm and the policy-maker basically correspond to those under rule-based commitment. However, in period 2, the policy maker is not bound by any rule when choosing a subsidy that maximizes welfare. In this case, she has an incentive for opportunistic policy-making, knowing that period-1 investment, $x_{1}$, is already sunk and will not react to her eventual choice. She further knows whether she is in the high- or the low-benefit state. Consequently, the statecontingent optimization problem for optimal welfare in period 2 is:

$$
W_{2 i}^{D}=\sum_{t=2}^{3}\left(\delta^{t-2}\left(V_{2}\left(q_{t i}\right)-L_{t}\left(s_{t i}, q_{t i}\right)+B_{t i}\left(q_{t i}\right)\right)\right)-C_{2}\left(x_{2 i}\right)
$$

This problem can again be solved by backward induction (see Appendix "Rule-Based Commitment Versus Discretion"). Comparing the resulting welfare level under discretion to that under rule-based commitment yields:

$$
W^{D *}=W^{R *}-\frac{\delta c_{2} l^{2}\left(b_{1}+E\left[b_{2}\right] \delta+(1+l) v(1+\delta)\right)^{2}}{2 c_{1}(1+2 l)\left(\mathrm{c}_{2} l^{2} \delta+\mathrm{c}_{1}(1+2 l)^{2}(1+\delta)^{2}\right)}
$$

Welfare under discretion is thus strictly lower than under rule-based commitment. Both policy approaches allow the incorporation of new knowledge on the external benefits. Consequently, the variance of future external benefits, $\sigma_{b}^{2}$-which drove the welfare loss under unconditional commitment above - is irrelevant for the choice between rule-based commitment and discretion. However, in contrast to rule-based (and unconditional) commitment, discretion opens up for opportunistic policy-making. In the presence of sunk period-1 investments, the policy-maker has an incentive in period 2 to choose a suboptimally low subsidy rate to reduce policy costs. This is foreseen by private investors, who respond with suboptimally low investments in period 1 . This underinvestment results in the welfare loss compared to rule-based commitment.

The welfare loss is strictly increasing in (expected) external benefits $b_{1}$ and $E\left[b_{2}\right]$ as well as in the consumer benefit $v$, all of which imply higher foregone benefits due to underinvestment. The welfare loss is decreasing with an increasing period-1 and/or a decreasing 
period-2 cost parameter, $c_{1}$ and $c_{2}$ respectively, i.e., with increasing exogenous technological progress. Technological progress implies that investments are shifted from period 1 to period 2, and underinvestment in period 1 becomes less important. The impact of the policy cost parameter $l$ on the welfare loss is analytically ambiguous. On the one hand, this parameter increases the incentive for opportunistic policy-making, and thus fosters underinvestment in period 1 under discretion. On the other hand, if policy costs become too large, the ex-ante optimal subsidies become so small that no investment is incentivized under either policy, and therefore the loss from discretion vanishes. Similarly, changes in the discount factor $\delta$ have an ambiguous effect on the welfare loss. On the one hand, an increasing discount factor (i.e., a lower discount rate) aggravates the negative impact of opportunistic policy-making in the future on period-1 investments. On the other hand, an increasing discount factor also implies that (under)investment in period 1-or a policy approach avoiding it-becomes relatively less important for long-run welfare across periods.

\subsubsection{Unconditional Commitment (C) Versus Discretion (D)}

We have seen that rule-based commitment is preferred to both unconditional commitment and discretion in terms of welfare. However, perfect rule-based commitment presents a more theoretical benchmark, as it is very demanding in terms of information and contracting (see, e.g., Lohmann 1992). Particularly, the policy-maker needs to be aware of the possible period-2 states. In practice, it is challenging to identify these states and to contract the corresponding state-contingent subsidies due to uncertainty and information constraints. At the very least, the policy-maker would therefore have to opt for committing to a strongly simplified set of states and subsidies. Unconditional commitment is one extreme case for this setting. On the other end of the possible spectrum, rule-based commitment may also degenerate into unconstrained discretion. This happens if the policy-maker deliberately opts for non-commitment in period 1, e.g., because she is aware of her ignorance about possible period-2 states. For practical policy-making, the key question therefore is whether it is still important that a policy-maker can commit, even though only unconditionally-or whether it is tolerable that she does not commit at all.

Combining (5) and (7) yields a welfare difference between unconditional commitment and full discretion that is ambiguous in sign:

$$
W^{C *}-W^{D *}=\frac{1}{2 c_{1} c_{2}(1+2 l)}\left(\frac{\delta c_{2}^{2} l^{2}\left(b_{1}+E\left[b_{2}\right] \delta+(1+l) v(1+\delta)\right)^{2}}{(1+4 l)(1+\delta)^{2}+l^{2}\left(4+9 \delta+4 \delta^{2}\right)}-\delta c_{1} \sigma_{b}^{2}(1+\delta)^{2}\right)
$$

This ambiguity is due to that fact that the policy-maker faces a trade-off when choosing between unconditional commitment and discretion. She either foregoes the benefit to incorporate new knowledge on external costs (cost of unconditional commitment) or accepts opportunistic future policy-making (cost of discretion).

To identify the impact of individual variables on the difference between unconditional commitment and full discretion, $W^{C *}-W^{D *}$, we can combine the observations made above when comparing both approaches to rule-based commitment. The difference is increasing (i.e., unconditional commitment becomes more favorable) with increasing consumer benefits from power generation, $v$, and increasing (expected) external benefits from clean power in both periods, $b_{1}$ and $E\left[b_{2}\right]$. Increases in these variables raise the cost of discretion. Yet, they do not alter the cost of unconditional commitment. 
Table 1 Parameter values assumed for the main scenario

\begin{tabular}{llll}
\hline & Value & Unit & Corresponding value in standard unit \\
\hline$\delta$ & 0.631 & & $4.5 \% \mathrm{p.a}$. \\
$v$ & 0.53 & $\mathrm{bn} € / \mathrm{GW}$ & $30 € / \mathrm{MWh}$ \\
$c_{1}$ & 0.0082 & $\mathrm{bn} € / \mathrm{GW}^{2}$ & $70 € / \mathrm{MWh}$ levelized capex at $200 \mathrm{GW}$ \\
$c_{2}$ & 0.0053 & $\mathrm{bn} € / \mathrm{GW}^{2}$ & $45 € / \mathrm{MWh}$ levelized capex at $200 \mathrm{GW}$ \\
$l$ & 0.3 & & \\
$b_{1}, b_{2}, E\left[b_{2}\right]$ & 0.92 & $\mathrm{bn} € / \mathrm{GW}$ & $70 € / \mathrm{tCO}_{2}$ \\
$b_{2 L}$ & 0.66 & $\mathrm{bn} € / \mathrm{GW}$ & $50 € / \mathrm{tCO}_{2}$ \\
$b_{2 H}$ & 1.18 & $\mathrm{bn} € / \mathrm{GW}$ & $90 € / \mathrm{tCO}_{2}$ \\
$\alpha$ & 0.5 & & \\
\hline
\end{tabular}

The difference is decreasing (i.e., discretion becomes more favorable) with an increasing variance of the external benefits $\sigma_{b}^{2}$. A higher variance increases the cost of unconditional commitment but does not affect the cost of discretion (discretion is most desirable in cases where $\alpha=0.5$, as this value maximizes variance in benefits for any given state benefit difference $\left.b_{2 H}-b_{2 L}\right)$. The difference also decreases with an increasing degree of technological change, i.e., a higher period-1 and/or a lower period- 2 cost parameter, $c_{1}$ and $c_{2}$, respectively. Technological progress increases the cost of unconditional commitment and decreases the cost of discretion.

It remains analytically ambiguous how the difference between unconditional commitment and discretion is affected by changes in the policy cost parameter $l$ and the discount factor $\delta$. That is, the ambiguity of both variables with respect to the cost of discretion can dominate their strictly decreasing $(l)$ and increasing $(\delta)$ effects on the costs of commitment.

\subsection{Numerical Illustration}

We complement our analytical results by a simple numerical application for investments in RES technologies for power generation, particularly wind power installed onshore in Europe. The primary intention of this numerical exercise is to understand how the analytical ambiguities may dissolve for realistic parameter values. The main parameter values are provided in Table 1 . We assume that each period consists of a decade. In this case, the discount factor $\delta=0.63$ corresponds to a modest annual discount rate of $4.5 \%$. The values of technological parameters are chosen to be within the ranges typical for modern onshore wind farms in Europe, as given in IRENA (2018). We assume levelized costs of electricity of roughly $70 € / \mathrm{MWh}$ for the 200th GW of installed capacity, rising linearly to $140 € /$ MWh for the 400th GW in period $1 .^{7}$ Technological progress reduces this cost function proportionally by some $36 \%$ in period 2 , so that the 200th GW has levelized costs of 45 $€ / \mathrm{MWh}$. The load-factor is assumed to be $20 \%$ throughout a 20 year lifetime of the plants (Ziegler et al. 2018). We use a captured electricity (wholesale) price of $30 € / \mathrm{MWh}$, which

\footnotetext{
7 Convexity could represent more expensive siting, including moving from onshore to offshore, and increased revenue cannibalization as higher penetration of correlated wind farms reduces productionweighted sales prices, cf. Sect. 2.
} 
Table 2 Equilibrium subsidy levels, investment levels, and welfare for the three policy scenarios

\begin{tabular}{lllll}
\hline Value & \multicolumn{3}{l}{ Policy scenario } & \\
\cline { 2 - 4 } & & $\begin{array}{l}\text { Rule-based } \\
\text { commitment }(\mathrm{R})\end{array}$ & $\begin{array}{l}\text { Unconditional } \\
\text { commitment (C) }\end{array}$ & Discretion (D) \\
\hline Subsidy level (€/MWh) & Period 1 & $s_{1}^{R *}=27.2$ & $s_{1}^{C *}=27.2$ & $s_{1}^{D *}=29.3$ \\
& Period 2 & $s_{2 H}^{R *}=36.6$ & $s_{2}^{C *}=27.2$ & $s_{2 H}^{D *}=32.4$ \\
& & $s_{2 L}^{R *}=17.8$ & & $s_{2 L}^{D *}=13.6$ \\
Investment level $(\mathrm{GW} /$ decade) & Period 1 & $x_{1}^{R *}=199$ & $x_{1}^{C *}=199$ & $x_{1}^{D *}=198$ \\
& Period 2 & $x_{2 H}^{R *}=361$ & $x_{2}^{C *}=310$ & $x_{2 H}^{D *}=338$ \\
& & $x_{2 L}^{R *}=259$ & & $x_{2 L}^{D *}=236$ \\
Welfare (bn€) & Over all periods & $W^{R *}=523.1$ & $W^{C *}=516.2$ & $W^{D *}=521.7$ \\
\hline
\end{tabular}

is somewhat below average wholesale prices observed in Europe (European Commission 2018), reflecting wind 'cannibalization', i.e., that the correlation of wind output across farms means wind farms tend to yield a lower-than-average market price for their power. We assume an emission intensity of $0.75 \mathrm{tCO}_{2} / \mathrm{MWh}$ for the conventional electricity which is replaced by electricity generation from wind power. This reflects that the marginal active power plant is typically coal-fired (around $1.0 \mathrm{tCO}_{2} / \mathrm{MWh}$ ) or gas-fired (around $0.5 \mathrm{tCO}_{2} /$ MWh) (e.g., IEA 2017). The value of $b_{1}=0.92 \mathrm{bn} € / \mathrm{GW}$ corresponds to an average value of $70 € / \mathrm{tCO}_{2}$ for emissions avoidance through wind energy. Benefits in period $2, b_{2 L}$ and $b_{2 H}$, correspond to a $50 \%$ chance for a low climate externality of $50 € / \mathrm{tCO}_{2}$ and a $50 \%$ chance of a higher externality of $90 € / \mathrm{tCO}_{2}$, with the same expected value as in period 1 (for a review of estimates, see Tol 2011). The policy cost parameter, $l$, is $30 \%$. This is in line with a typical marginal welfare cost of taxes (e.g., Browning 1987), which are needed to fund the subsidy to wind power generation. Based on these assumptions we get the numerical results provided in Table 2 .

We note two key insights from Table 2: first, in this basic setting with uncertain benefits, discretion outperforms unconditional commitment. This result points to the fact that with the chosen parameter values, benefits from flexibility dominate: the welfare gain from getting the benefit right more than outweighs the cost of opportunistic policy-making aiming at limiting the financing burden of subsidies. The sensitivity analysis provided in Appendix "Sensitivity Analyses for Numerical Illustration" shows that this finding is robust across reasonable ranges for the (expected) external benefit of clean power generation $\left(b_{1}, E\left[b_{2}\right]\right)$, the discount factor $(\delta)$, the rate of exogenous technological progress (i.e., the share by which the cost parameter $c_{2}$ is below $c_{1}$ ), and thepolicy cost $l$.

Second, the differences in welfare between the policy scenarios are generally very small. With uncertain benefits, discretion is only by $1 \%$ superior to unconditional commitment in terms of welfare. Moreover, both unconditional commitment and discretion come very close to the superior policy approach of rule-based commitment, with welfare losses of only $1.3 \%$ and $0.3 \%$, respectively. This suggests that the optimal choice between commitment and discretion is overall a minor issue for policy-making in our basic setting. This becomes particularly evident when we compare the policy outcomes to welfare in an unregulated market setting, amounting to 399.5 bn€. Implementing a climate policy is incomparably more decisive for overall welfare than the way policy-makers commit to it over time. 


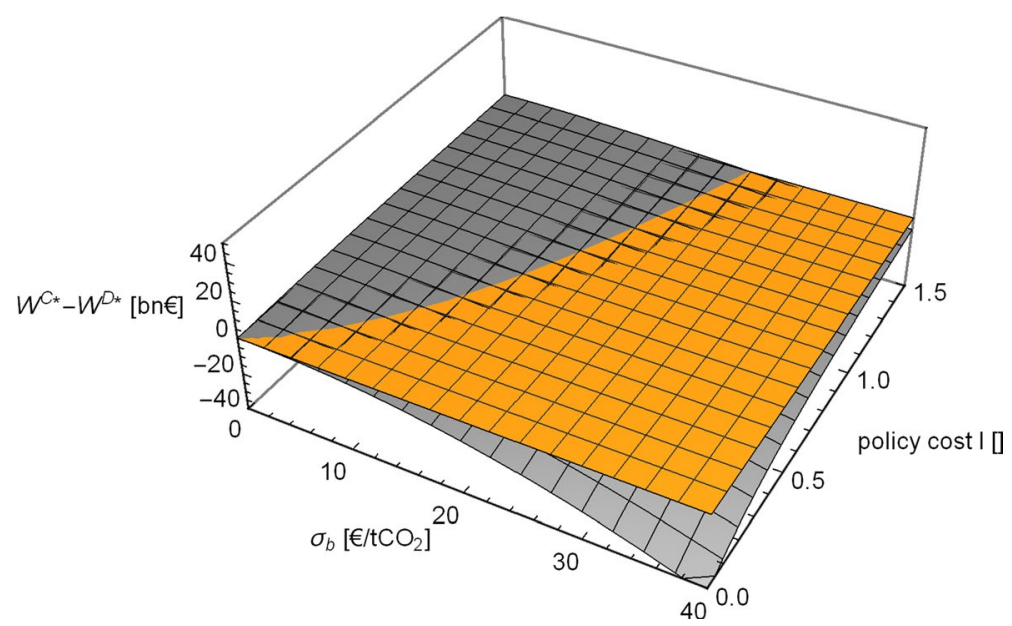

Fig. 1 Welfare impact of commitment $W^{C *}-W^{D *}$ : Sensitivity to policy cost $l$ and standard deviation of the external benefit $\sigma_{b}$ (yellow plain shows the zero level)

\section{Uncertain External Benefits: A More Realistic Approach}

We now relax three important assumptions underlying the basic setup above: we analyze how our policy scenarios compare (a) if uncertainty of the external benefits resolves only partially over time, (b) if the response of future policy-makers to certain states of the world is uncertain for today's policy-makers and firms, or (c) if firms are risk-averse. Making these adjustments, we re-assess the welfare comparison between unconditional commitment and discretion, which is analytically ambiguous.

\subsection{Partial Resolution of Uncertainty}

So far, we have assumed that the uncertainty regarding the external benefits of deploying the low-carbon technology vanishes completely at the beginning of period 2. However, in reality, uncertainty is likely to decline only partially from one period to another. And for short periods, the reduction in uncertainty may in fact be very small (see, e.g., Kelly and Kolstad 1999; Kelly and Tan 2015; Roe and Baker 2007). In our modeling framework, the case of uncertainty resolving only partially over time corresponds conceptually to the case where a small initial uncertainty vanishes completely at the beginning of period 2 . This is due to the fact that the variance in external benefits, $\sigma_{b}^{2}$, has a linear effect on the welfare difference between unconditional commitment and discretion [see Eq. (8)]. Consequently, the welfare effect of a reduction in uncertainty is independent of the initial level of uncertainty. Thus, the impact of incomplete reduction of uncertainty can be understood by examining how sensitively the welfare difference between unconditional commitment and discretion responds to changes in the degree of uncertainty. This sensitivity is illustrated in Fig. 1.

With period 1 representing 10 years in our calibration, it seems plausible that the actual reduction in uncertainty materializing at the beginning of period 2 may be very small 
indeed. If uncertainty does not reduce substantially from period 1 to 2 , the potential benefits of discretion are minor. Figure 1 underpins numerically how unconditional commitment becomes more favorable in terms of welfare with decreasing levels of uncertainty (or of uncertainty resolution). If uncertainty is small, unconditional commitment outperforms discretion for reasonable values of policy costs (e.g., $l>0.3$ ). Yet, Fig. 1 also shows that the welfare gain from unconditional commitment is rather small for a given small degree of uncertainty (resolution), even for higher levels of policy costs.

\subsection{Political Uncertainty (U)}

We have also assumed so far that today's policy-makers and firms can perfectly foresee how future policy-makers respond to different states of the world-even though these states may be uncertain in terms of external benefits. However, the response of future policy-makers to a certain state of the world is subject to uncertainty itself. This may particularly hold true if future policy-makers are not perfectly benevolent. Future (possibly opportunistic) policy choices may not be based on an intra-temporal social optimization approach which in period 2 balances (then more certain) benefits from RES deployment and costs (investment costs, policy costs). For example, future policy makers may also strive to satisfy their constituencies to ensure re-election (Kirchgässner and Schneider 2003). If allowed discretion, "green" ("non-green") policy-makers may set the level of ambition of climate policy sub-optimally high (low). We here explore the implications of such political uncertainty for the trade-off between unconditional commitment $(U C)$ and discretion $(U D)$.

To capture political uncertainty, we assume that, absent any commitment, the future government may deviate from the theoretically subgame-perfect levels when setting the period-2 subsidy. An alternative interpretation of the situation is that a current policymaker, with an own taste she optimizes for, takes into account the likely different preferences of a future policy-maker. Which type of policy-maker will be in power in period 2 is difficult to predict for the policy-maker in power in period 1 . We therefore model political uncertainty as noise surrounding future policy decisions, and not as a directed bias. ${ }^{8}$ Hence, we assume symmetric deviations across two states $j=\{H, L\}$, with $H$ and $L$ for the high- and low-subsidy preferences of future policy-makers. If, for an uncommitted government, $s_{2 i}^{U D *}$ was the optimal subgame-perfect period-2 subsidy for a given benefit state $i$, then it (or its period-2 counterpart) would choose $s_{2 i, H}^{U D}=s_{2 i}^{U D *}+u$ or $s_{2 i, L}^{U D}=s_{2 i}^{U D *}-u$, with $u$ the magnitude of the directed subsidy deviations. We rule out this type of period-2 deviations in the commitment case. We therefore have $W^{U C *}=W^{C *}$. Period-2 deviations are known unknowns in period-1, that is, non-committing period-1 planning takes into account that the period- 2 policies exhibit some uncertainty. The preference of the actual policymaker in power is revealed at the beginning of period-2, i.e., before period- 2 investment choices are made. The solution approach corresponds to that outlined for discretion above. The major difference consists in the fact that the policy-maker and the private investor now consider four possible states for period $2,[\cdot]_{2 i, u}$, when making their policy and investment choices.

\footnotetext{
8 This means, in any given state of the world, there will be (directed) bias in the period-2 policy making, but as of period 1 the direction remains unknown.
} 


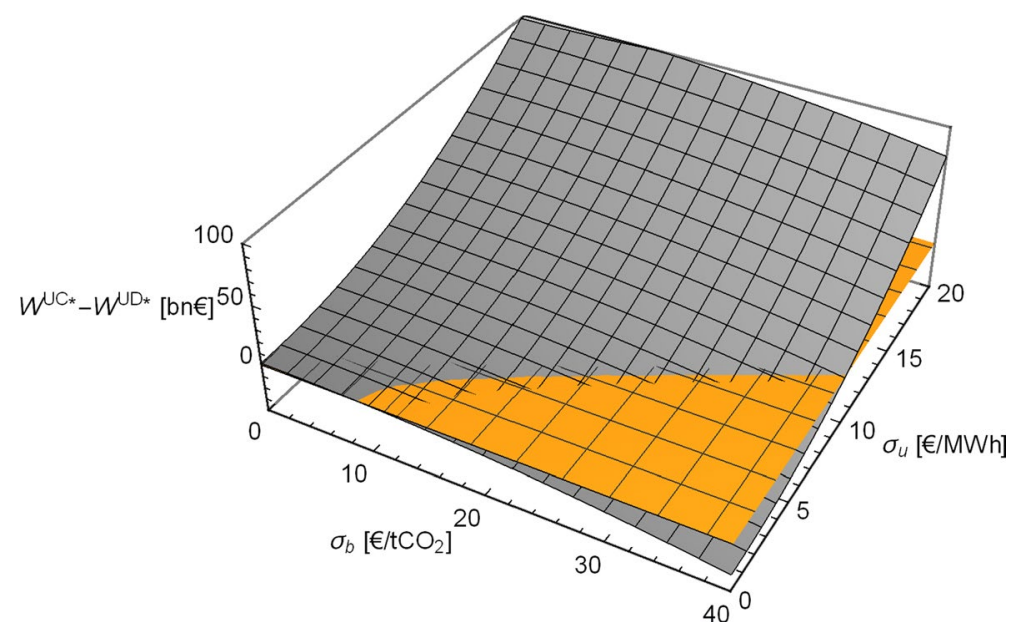

Fig. 2 Welfare impact of commitment with political uncertainty $\left(W^{U C *}-W^{U D *}\right)$ : Sensitivity to standard deviation of the benefit $\sigma_{b}$ and of the political uncertainty $\sigma_{u}$ (yellow plain shows the zero level)

We find that, within this framework, the expectation values for subsidy and investment, aggregated over the future government's possible preferences, equal those of the case without political uncertainty:

$$
s_{1}^{U D *}=s_{1}^{D *} \quad x_{1}^{U D *}=x_{1}^{D *} \quad E_{u}\left[s_{2 i, u}^{U D *}\right]=s_{2 i}^{D *} \quad E_{u}\left[x_{2 i, u}^{U D *}\right]=x_{2 i}^{D *}
$$

The policy imprecision under political uncertainty does, however, have a cost. This is reflected in the overall welfare, which becomes

$$
W^{U D *}=W^{D *}-\frac{2 u^{2}(1+l) \delta(1+\delta)^{2}}{c_{2}}
$$

Thus, political uncertainty strictly reduces the welfare under discretion, and makes discretion relatively less attractive compared to commitment. This reduction is proportional to the variance of subsidy deviations, $\sigma_{u}^{2}=u^{2}$. In our numerical example, the loss from a period-2 policy subsidy standard deviation $\sigma_{u}=u$ of just around $10 € / \mathrm{MWh}$ (this may be a plausible magnitude; in our main scenario the optimal subsidy rate for period 2 varies from 13 to $37 € / \mathrm{MWh}$ ) is enough to make unconditional commitment superior to discretion for all plausible ranges of benefit uncertainty, as illustrated in Fig. 2. Thus, the benefit of safeguarding against political uncertainty under unconditional commitment is higher than the benefit of incorporating new knowledge on the external benefit under discretion. Certainly, this result hinges on the range of benefit uncertainty considered. For extremely high benefit uncertainty-much larger than the $40 € / \mathrm{tCO}_{2}$ considered in Fig. 2-discretion can turn out to be welfare-superior, despite high political uncertainty. 


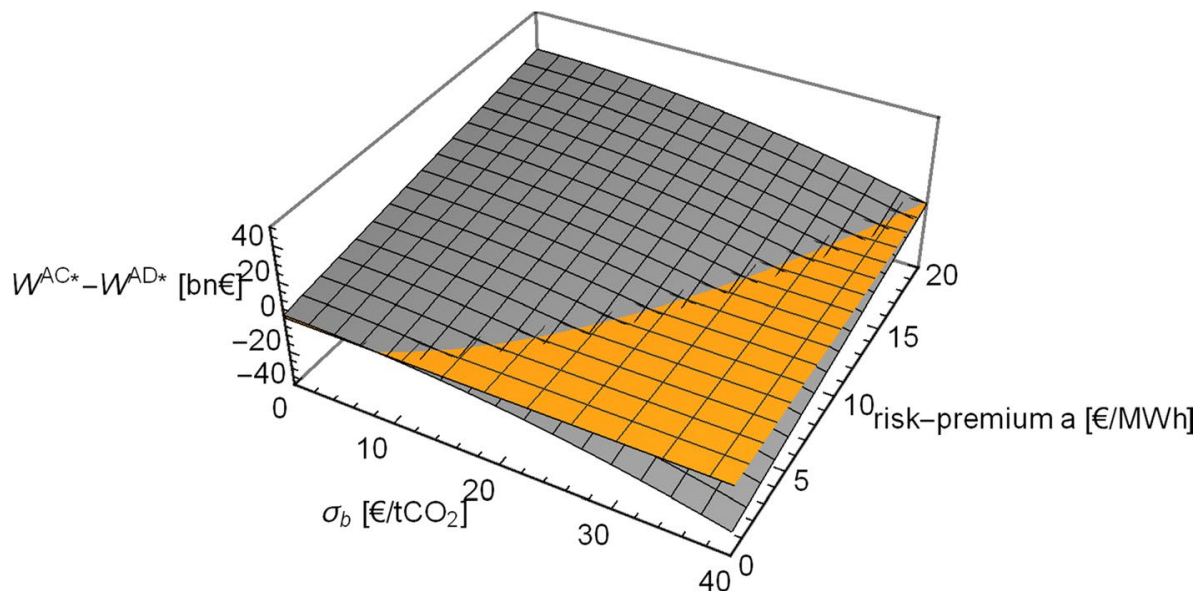

Fig. 3 Welfare impact of commitment with risk aversion $\left(W^{A C *}-W^{A D *}\right)$ : sensitivity to standard deviation of the benefit $\sigma_{b}$ and risk premium $a$ (yellow plain shows the zero level)

\subsection{Risk Aversion}

We now assume that private investors are risk-averse, and therefore exhibit a certain skepticism towards uncertain future subsidies. To capture risk aversion in our model, firms' revenue expectations for period 2 and 3 are reduced by a risk premium $a$ in the case of discretion. For the case of commitment $(A C)$ all revenues are known. We therefore assume that in this case no risk premium applies in period 2 and 3, i.e., $a=0$, and, consequently, $W^{A C *}=W^{C *}$. For discretion $(A D)$, in contrast, one can readily verify that the firms behave according to the following changed first-order conditions for investment:

$$
\begin{aligned}
& x_{1}^{A D}=\frac{s_{1}+v+\delta\left(E\left[s_{2}\right]-a+v\right)}{c_{1}} \\
& x_{2 i}^{A D}=\frac{\left(s_{2 i}+v\right)(1+\delta)-\delta a}{c_{2}}
\end{aligned}
$$

Using this behavioral rule for substitution in the policy-maker's welfare function from the basic case of discretion, $W^{D}$, and solving the game analogously to that case, we naturally find the same welfare as in the basic case of discretion when $a=0,\left.W^{A D *}\right|_{a=0}=W^{D *}$, and a reduction of the welfare as $a$ takes a (reasonable) positive value (see details in Appendix "Welfare Analysis of Policy Scenarios with Uncertain External Benefits and Risk Aversion"). Figure 3 illustrates how the increasing risk premium $a$ further decreases the case for discretion. For plausible values of the resolved benefit uncertainty, commitment appears clearly superior to discretion, even for a relatively low risk-premium $a$. In these cases, the benefit of safeguarding the security of investment under commitment dominates the benefits of incorporating new knowledge about external benefits. In other words, for discretion to become welfare-superior, benefit uncertainty needs to be relatively high. 


\section{Uncertain Costs of Low-Carbon Technologies}

There is not only substantial uncertainty of the external benefits of market-based instruments, e.g., in terms of the avoided social costs of carbon. The evolution of the costs of low-carbon technologies is also highly uncertain. This uncertainty is primarily pointed out for the costs of renewable energy sources, for which learning curves have proven to be hardly predictable (Rubin et al. 2015). In the remainder of this section, we discuss how cost uncertainty may affect the choice between commitment and discretion in climate policy (for a more formal analysis, see Habermacher and Lehmann 2017). We assume in turn that the benefit parameter $b_{2}$ is certain.

In our model, uncertainty of future technology costs can be incorporated by assuming that the cost parameter $c_{2}$ is uncertain at the beginning of period 1 and depends on a future state $i \in\{H, L\}$ for period 2: It is $c_{2 H}$ and $c_{2 L}$ in the high-cost and low-cost states $H$ and $L$ respectively. It can readily be seen that cost uncertainty will not affect the choice between commitment and discretion in the simplistic Pigouvian setting we have so far considered. The optimal period-2 policy rule in the deterministic setting-which would be $s_{2}=\left(b_{2}-l v\right) /(1+2 l)$, following Eqs. (10) and (14) in Appendix "Rule-Based Commitment Versus Unconditional Commitment"-does not hinge on the cost parameter $c$. In this setting, there is therefore no benefit from adapting the subsidy to technology costs. Consequently, commitment will be strictly superior to discretion even if the future costs of the low-carbon technology are uncertain.

This observation is subject to two important caveats. First, it has been derived under the assumption of linear external benefits from adopting the low-carbon technology. In reality, with non-linear external benefits, cost uncertainty has an effect on the optimal level of ambition of the market-based instrument (see, e.g., Weitzman 1974). In this case, there can be a (second-order) benefit from adjusting the period- 2 price mechanism to incorporate new knowledge on the actual level of period-2 technology costs. Consequently, the optimal choice between unconditional commitment and discretion may become ambiguous in the presence of cost uncertainty if benefits are non-linear.

Second, policy implications may be different if the market-based instrument does not follow the Pigouvian logic of internalizing an external benefit. Instead, it may be meant to attain a politically set technology deployment target at least cost [in line with Baumol and Oates' (1971) standard-price approach]. Such an approach is widespread political practice-consider only the EU's explicit RES deployment targets for 2020 and 2030 (European Commission 2014). Under a standard-price approach, the level of ambition for the market-based policy is not set with respect to the external benefit but the shadow price of the target. This shadow price is a function of technology costs and related uncertainty. Under this approach, unconditional commitment is inferior to discretion as long as the target is binding. The explanation is simple: With unconditional commitment, the period-2 level of ambition for the market-based instrument needs to be chosen in period 1 such that the target is met in period 2 even if deployment costs turn out to be high, i.e., if $c_{2 i}=c_{2 H}$. This approach implies in turn that the chosen level of ambition for the market-based instrument runs the risk of costly overshooting the technology deployment target if deployment costs turn out to be low in period 2. At the same time, rule-based commitment and discretion become equivalent in a standard-price setting. By setting the level of ambition for period 1, the policy-maker with either approach automatically commits to the state-contingent level of ambition for the market-based instrument in period 2 that guarantees the target to be met. Even if the policy-maker can 
fully adjust the period-2 market-based instrument after she has learned about period-1 investments and the actual state of the world, her choice of the state-contingent period-2 level of ambition is inevitably predetermined by here choice in period 1 . Thus, with a fixed technology deployment target, the incentive for the policy-maker to behave opportunistically vanishes. The target serves as a commitment device for the market-based instrument. In this case, discretion only generates the benefit from adjusting the market-based instrument to the actual state, and therefore is equivalent to rule-based commitment. Overall, this implies that discretion rules out unconditional commitment in a standard-price setting. Certainly, this only holds as long as the technology deployment target itself is not subject to discretion-which may not always be realistic in practice.

\section{Discussion}

Overall, our analytical and numerical analyses suggest that if the first-best approach of rule-based commitment is not feasible for climate policy, unconditional commitment should be favored over discretion in many cases-despite forgoing the benefits of being able to adjust policies over time. The case for commitment may be further strengthened if several here ignored caveats to discretion are taken into account. Three examples may illustrate this. First, we have assumed technological progress to occur exogenously. However, the costs of period- 2 investments may also decrease with increasing period- 1 investments due to endogenous learning. In this case, the social loss of underinvestment in period 1 due to climate policy discretion is aggravated. Second, we have neglected that discretion (and rule-based commitment) may bring about significant transaction costs in period 2. These arise because with every policy revision information needs to be gathered and tedious political bargaining and decision-making processes are required. This again weakens the case for discretion. Third, we disregard issues of political credibility. In fact, discretionary decision-making may undermine the credibility of a government more broadly. Private actors may not only draw political decisions related to climate policy into question but also those taken in other policy fields (e.g., May and Chiappinelli 2018). In this way, discretion in climate policy may create additional costs to society by impairing investments contingent on other public policies.

What lessons can be learned from our analysis for real-world climate policy-making? First of all, it seems fair to assume that the discretionary patterns of climate policiesand particularly of RES support schemes-observed in many countries reduce welfare. Against this background, it is important that at least many RES support schemes do provide a certain degree of commitment even though the RES subsidy levels vary from year to year. With some exceptions, subsidy adjustments are not undertaken retrospectively but only for newly installed RES plants. Moreover, some upcoming policy adjustments are announced ex ante, e.g., by legally defined digression rates for subsidies, or breathing caps, which adjust a subsidy once a certain deployment threshold is reached. Analytically, these approaches exhibit similarities to rule-based commitment, the optimal solution in our model. Certainly, such commitment devices are more difficult to implement for direct carbon pricing approaches. In this respect, commitment devices that go beyond mere policy design become important. One example is the delegation of climate policy decisions to an independent authority (see, e.g., Brunner et al. 2012; Helm et al. 2003; Perino 2010). At the same time, our analysis also implies that climate policy adjustments must not be ruled out in all circumstances. If the benefits of discretion are high (because uncertainty 
of external benefits of climate policy is expected to decline significantly in due time) and costs of discretion are low (because, for example, an independent authority reduces the threat of opportunistic policy-making), allowing future RES policy adjustments may make sense. Similarly, we have shown that if policy makers credibly commit to a future technology target, e.g., for RES deployment, and the costs of attaining this target are uncertain, it may be reasonable to allow for adjusting the market-based instrument to attain the target at least cost. Nevertheless, the welfare differentials between our policy scenarios are generally rather small. This suggests that choosing an adequate ambition for climate policy today is more important than the way policy makers commit to it across time.

Our study does not explicitly address that the optimal choice between commitment and discretion may also depend on the fundamental design of policy instruments. For example, the societal need for adjustments (and thus the benefits of discretion) will hinge on the degree of "built-in" flexibility, i.e., the ability of policy instruments to respond to new knowledge without actually changing the policy design. In this respect, there may be differences between price and quantity instruments as well as between technology-neutral and technology-specific regulatory approaches. Moreover, the eventual degree of political opportunism may vary across policy instruments if they distribute policy costs and benefits differently across political stakeholder groups. A more comprehensive qualitative discussion of such issues is provided by Gawel and Lehmann (2019).

Our relatively simple modeling is also subject to various technical constraints. Our partial equilibrium framework focusing on investments into low-carbon technologies ignores impacts of climate policy commitment and discretion on (similarly long-term and irreversible) investments in the carbon-intensive power sector and beyond the power sector. In addition, our analysis could be refined with a continuous probability distribution for future states (rather than our two discrete states). This could allow investigating intermediate solutions between unconditional commitment and discretion, i.e., where the policy-maker commits to a limited number of discrete state-contingent subsidy paths which allow only an imperfect mapping of the continuous range of possible states (unconditional commitment to only one subsidy rate is an extreme case of this approach). Yet, we would expect that this refinement will primarily affect the size, not the sign, of the welfare differential between commitment and discretion. Similarly, a more elaborate analysis could apply a continuous time model (instead of our discrete time model with three periods). While we do not expect that this changes the trade-off between commitment and discretion fundamentally, it may allow addressing additional, interesting research questions, such as the optimal length of commitment in the presence of uncertain benefits and costs.

\section{Conclusion}

Adequate levels of private investment demand stable political frameworks. This is especially important for long-lived infrastructure investments. The corresponding paradigm of long-term political stability and policy commitment can, however, be challenged: if benefits and costs of policies are uncertain ex ante, the failure to revise policies when new information becomes available also produces costs. There is thus a trade-off between policy commitment encouraging investment and discretion allowing to update policies in the future in line with new information. Our analysis focuses on climate policy, a policy domain where this trade-off is significant. Large-scale investments into low-carbon technologies are only viable with some clarity about the medium-term evolution of policy 
support. However, uncertainty of the social cost of carbon and technology costs equally mean it cannot be excluded that policies agreed today warrant adjustments in a few years when new information becomes available.

In a dynamic partial equilibrium framework that can account for political opportunism, climate or technology uncertainty, and risk aversion, committing to a policy path with predefined adjustments to new information is found to be welfare-maximizing. Politically contracting such contingencies in detail seems implausible for the case of climate policy. Instead, a simpler commitment to a fixed policy path, or-on the other extreme-discretion to freely adjust future policy to new information, seem more realistic. Analytically, the choice between the latter two strategies is ambiguous. Yet, our numerical application, calibrated roughly to a case of subsidies for wind turbine deployment, reveals that commitment may outperform discretion under realistic assumptions. The slowness by which climate uncertainty resolves over time, political uncertainty, and risk aversion strengthen the case for commitment.

If the major source of uncertainty is technology costs rather than climate benefits, the case for or against commitment is influenced by whether the political aim is really to contain climate change or to achieve a fixed renewables deployment target at least cost. In the latter case, we see that discretion appears more favorable if the requirement to achieve a strict target limits issues of opportunistic policy-making.

Overall, the welfare differences we find between the policy scenarios are often significant but limited to a few percent of the absolute overall system benefits of the renewables considered. This points to the fact that choosing the right level of ambition for climate policy today may be more important than the exact way this policy is committed to.

Acknowledgements Open Access funding provided by Projekt DEAL. Florian Habermacher's independent research was supported by Aurora Energy Research. Paul Lehmann's research was funded by Deutsche Forschungsgemeinschaft (DFG) under Grant LE 3746/1-1 as well as by Bundesministerium für Bildung und Forschung (BMBF) under Grant 01UU1703. We are very grateful for valuable comments and suggestions made by Erik Gawel, Reyer Gerlagh, Cameron Hepburn and Alex Teytelboym. Our paper also benefited from discussions during research seminars held at the Institute for New Economic Thinking at the University of Oxford, the Helmholtz Centre for Environmental Research-UFZ, the University of Kiel, the University of Hamburg as well as the Scientific Society of German-speaking Environmental and Resource Economists (AURÖ).

Open Access This article is licensed under a Creative Commons Attribution 4.0 International License, which permits use, sharing, adaptation, distribution and reproduction in any medium or format, as long as you give appropriate credit to the original author(s) and the source, provide a link to the Creative Commons licence, and indicate if changes were made. The images or other third party material in this article are included in the article's Creative Commons licence, unless indicated otherwise in a credit line to the material. If material is not included in the article's Creative Commons licence and your intended use is not permitted by statutory regulation or exceeds the permitted use, you will need to obtain permission directly from the copyright holder. To view a copy of this licence, visit http://creativecommons.org/licenses/by/4.0/.

\section{Appendix}

\section{Welfare Analysis of Policy Scenarios with Uncertain External Benefits}

\section{Rule-Based Commitment Versus Unconditional Commitment}

For rule-based commitment, maximizing (1) with respect to investment levels in period 1 and 2 yields the firm's reaction functions as first-order conditions: 


$$
x_{1}^{R}\left(s_{1}, E\left[s_{2}\right]\right)=\frac{s_{1}+v+\delta\left(E\left[s_{2}\right]+v\right)}{c_{1}} \quad x_{2 i}^{R}\left(s_{2 i}\right)=\frac{\left(s_{2 i}+v\right)(1+\delta)}{c_{2}},
$$

where $E\left[s_{2}\right]$ is the expectation value for $s_{2}, E\left[s_{2}\right]=s_{2 H} \alpha+s_{2 L}(1-\alpha)$.

Substituting (9) into (2), deriving the first-order conditions for the welfare-maximizing subsidies $s_{1}$ and $s_{2 i}$, and solving the resulting equation systems yields the optimal, state-contingent subsidy schedule:

$$
s_{1}^{R *}=\frac{b_{1}-l v}{1+2 l} \quad s_{2 i}^{R *}=\frac{b_{2 i}-l v}{1+2 l}
$$

Simply, the policy-maker commits to adopting a state-contingent Pigouvian subsidy of the marginal external benefit, adjusted for the marginal policy cost produced by the subsidy.

Inserting (10) into (9) gives the state-contingent optimal investment levels, with expectation and state-contingent values of $b_{2}$ in period 1 and 2, respectively:

$$
x_{1}^{R *}=\frac{b_{1}+\delta E\left[b_{2}\right]+(1+\delta)(1+l) v}{c_{1}(1+2 l)} \quad x_{2 i}^{R *}=\frac{(1+\delta)\left(b_{2 i}+(1+l) v\right)}{c_{2}(1+2 l)}
$$

Substituting (10) and (11) into (2), we can derive the optimal welfare under rule-based commitment:

$$
W^{R *}=W^{*}+\frac{\sigma_{b}^{2} \delta(1+\delta)^{2}}{2 c_{1} c_{2}(1+2 l)}
$$

with

$$
\begin{aligned}
W^{*}= & \frac{1}{2 c_{1} c_{2}(1+2 l)} \operatorname{bigg}\left(b_{1}^{2} c_{2}+c_{1}\left(b_{2}+v(1+l)\right)^{2} \delta(1+\delta)^{2}+2 b_{1} c_{2}\left(b_{2}^{d} \delta+(1+l) v(1+\delta)\right)\right. \\
& \left.+c_{2}\left(b_{2}^{d} \delta+(1+l) v(1+\delta)\right)^{2}\right)
\end{aligned}
$$

indicating the welfare optimum in a deterministic case with known future damage $b_{2}^{d}=E\left[b_{2}\right] \cdot{ }^{9}$ It can be shown that the outcome under rule-based commitment corresponds to the first-best if the market-based instrument does not generate welfare-reducing policy costs, i.e., if $l=0$.

The firm's reaction functions with unconditional commitment correspond to those under rule-based commitment, (9), with the expectation value of the period-2 subsidy replaced by its deterministic equivalent $s_{2}$. Substituting these reaction functions into (4), deriving the first-order conditions for the welfare-maximizing subsidies $s_{1}$ and $s_{2}$, and solving the resulting equation system, yields the optimal subsidies,

$$
s_{1}^{C *}=s_{1}^{R *}=\frac{b_{1}-l v}{1+2 l} \quad s_{2}^{C *}=\frac{E\left[b_{2}\right]-l v}{1+2 l}
$$

again corresponding to the loss-adjusted Pigouvian level, but here with a deterministic $s_{2}^{C *}$ as a function of the damage expectation value. Substituting these subsidies back into the firm's reaction functions yields the optimal investment levels for both periods. These also

9 See Habermacher and Lehmann (2017) for a detailed analysis of the deterministic case. 
correspond to $x_{t}^{R *}$ from (11), with $b_{2 i}$ being replaced by the expectation value $E\left[b_{2}\right]$. Substituting these optimal investment levels into (4) and considering (12) yields the welfare comparison provided in Eq. (5).

\section{Rule-Based Commitment Versus Discretion}

For discretion, the firm's first-order conditions for profit-maximizing investment in period 2 take the same form as those derived for rule-based commitment in Eq. (9). Substituting (9) into (6), we can derive the welfare-maximizing subsidies for period 2 in either state as a function of period-1 investment:

$$
s_{2 i}^{D}\left(x_{1}\right)=\frac{b_{2 i}(1+\delta)^{2}-l\left(c_{2} x_{1}+v(1+\delta)^{2}\right)}{(1+2 l)(1+\delta)^{2}}
$$

Inserting (15) back into (9) gives the optimal investment levels in period 2 as a function of period-1 investment:

$$
x_{2 i}^{D}\left(x_{1}\right)=\frac{b_{2 i}(1+\delta)^{2}+(1+l) v(1+\delta)^{2}-c_{2} l x_{1}}{c_{2}(1+2 l)(1+\delta)}
$$

Using (15) and (16), the firm's first-order condition for optimal investment in period 1 given in (9) can be adjusted, and we can derive the optimal period-2 subsidy as well as the (state-contingent) investment levels in periods 1 and 2 as functions of the period- 1 subsidy:

$$
\begin{aligned}
s_{2 i}^{D}\left(s_{1}\right) & =\frac{b_{2 i}}{1+2 l}-\frac{l\left(c_{2}\left(s_{1}+v\right)+c_{2}(E[b]+v(1+2 l)) \delta /(1+2 l)+c_{1} v(1+\delta)^{2}\right)}{c_{2} l \delta+c_{1}(1+2 l)(1+\delta)^{2}} \\
x_{1}^{D}\left(s_{1}\right) & =\frac{(1+\delta)^{2}\left((1+2 l)\left(s_{1}+v\right)+(E[b]+v(1+l)) \delta\right)}{c_{2} l \delta+c_{1}(1+2 l)(1+\delta)^{2}} \\
x_{2 i}^{D}\left(s_{1}\right) & =\frac{(1+\delta)\left(b_{2 i}\left(c_{2} l \delta /(1+2 l)+c_{1}(1+\delta)^{2}\right)+c_{1}(1+l) v(1+\delta)^{2}-c_{2} l\left(\left(s_{1}+v\right)+E[b] \delta /(1+2 l)\right)\right)}{c_{2}\left(c_{2} l \delta+c_{1}(1+2 l)(1+\delta)^{2}\right)}
\end{aligned}
$$

Substituting (17) into the policy maker's welfare function, which is identical to (2), and maximizing welfare with respect to the period-1 subsidy yields the optimal subsidy for period 1, and in turn the optimal state-contingent subsidies for period 2:

$$
\begin{aligned}
& s_{1}^{D *}=\frac{1}{n_{1}}\left(b_{1}\left(c_{1}(1+2 l)(1+\delta)^{2}+c_{2} \delta l\right)+l\left(c_{2} \delta\left(v+\frac{\delta\left(E\left[b_{2}\right]+v(1+l)\right)(1+l)}{1+2 l}\right)-c_{1}(1+2 l) v(1+\delta)^{2}\right)\right) \\
& s_{2 i}^{D *}=\frac{1}{n_{1}}\left(\left(b_{2 i}-l v\right) c_{1}(1+2 l)(1+\delta)^{2}-l c_{2}\left(b_{1}+v(1+l)+\delta\left(E\left[b_{2}\right]+b_{2 i} 2 \alpha+\frac{v(1+3 l(1+l))-b_{2 i} l}{1+2 l}\right)\right)\right)
\end{aligned}
$$

where $n_{1} \equiv \mathrm{c}_{2} l^{2} \delta+\mathrm{c}_{1}(1+2 l)^{2}(1+\delta)^{2}>0$.

Using the firm's reaction functions, we find the corresponding optimal investment levels as: 


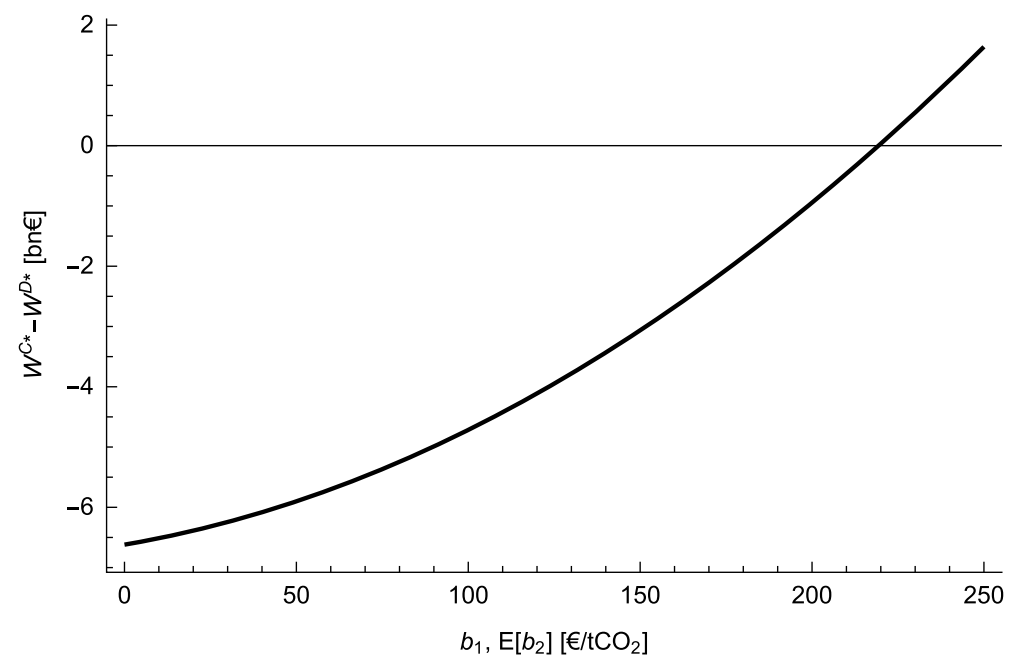

Fig. 4 Welfare impact of commitment $W^{C *}-W^{D *}$ : sensitivity to (expected) external benefit $b_{1}$ or $E\left[b_{2}\right]$

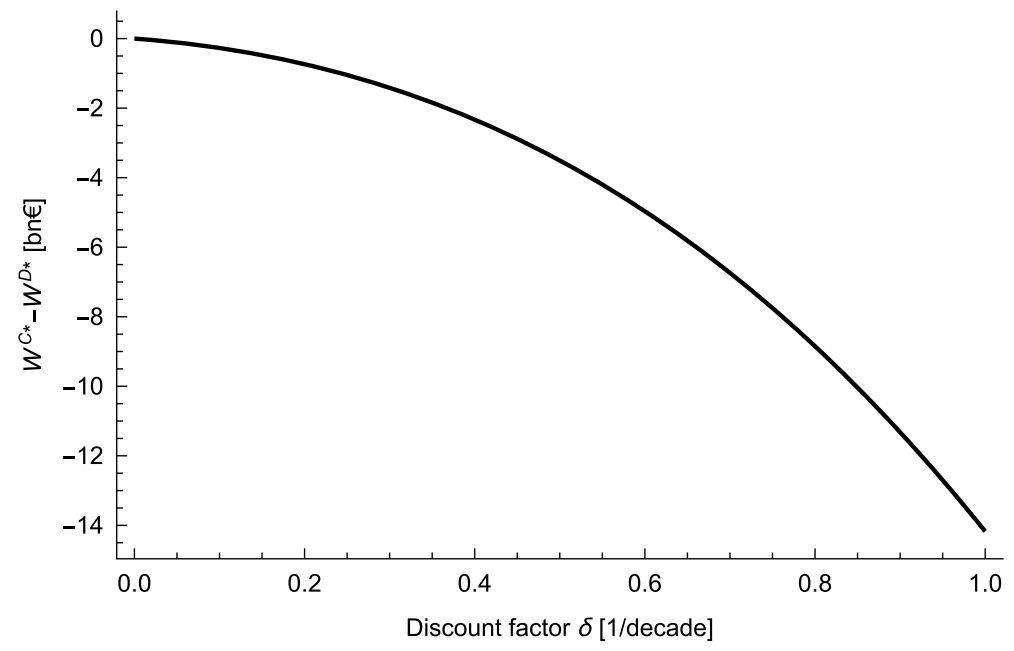

Fig. 5 Welfare impact of commitment $W^{C *}-W^{D *}$ : sensitivity to discount factor $\delta$

$$
\begin{aligned}
x_{1}^{D *}= & \frac{1}{n_{1}}\left((1+2 l)(1+\delta)^{2}\left(b_{1}+E\left[b_{2}\right] \delta+(1+l) v(1+\delta)\right)\right) \\
x_{2 i}^{D *}= & \frac{1+\delta}{n_{1} c_{2}}\left(v(1+l)\left(c_{1}(1+2 l)-c_{2} l\right)-b_{1} c_{2} l+(2+\delta) c_{1} \delta v(1+l)(1+2 l)\right. \\
& \left.-c_{2} \delta l\left(E\left[b_{2}\right]+\frac{l\left(2 l v-b_{2 i}\right)}{1+2 l}+v+2 \alpha b_{2 i}\right)+b_{2 i} c_{1}(1+2 l)(1+\delta)^{2}\right)
\end{aligned}
$$




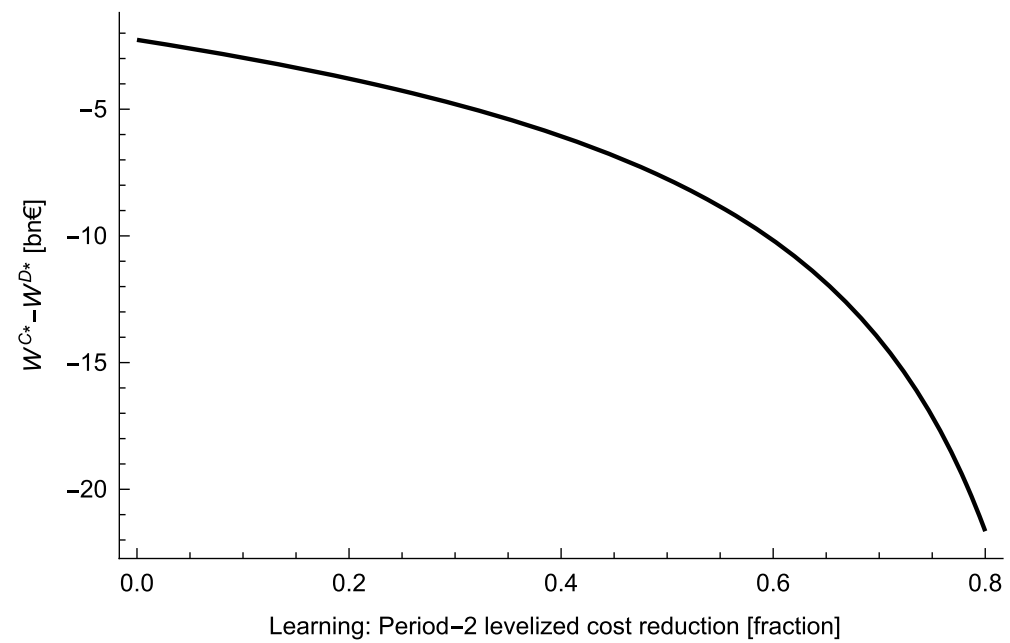

Fig. 6 Welfare impact of commitment $W^{C *}-W^{D *}$ : sensitivity to technological progress (relative change of cost parameter from $c_{1}$ to $c_{2}$ )

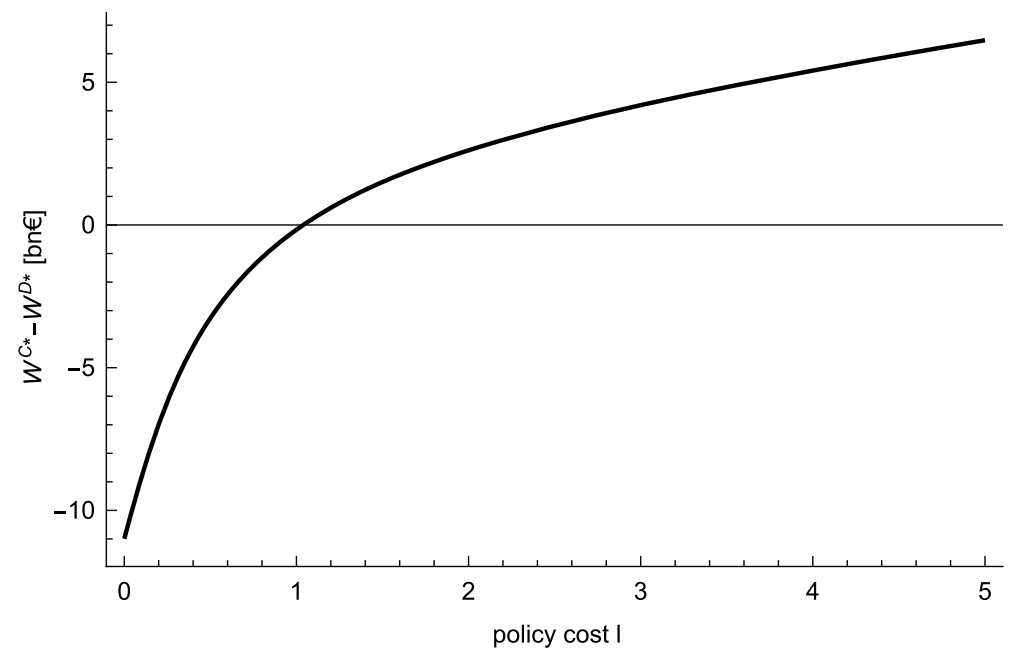

Fig. 7 Welfare impact of commitment $W^{C *}-W^{D *}$ : Sensitivity to policy cost $l$

Substituting (18) and (19) into (2) and considering (12) yields the welfare comparison between rule-based commitment and discretion provided in Eq. (7).

\section{Sensitivity Analyses for Numerical Illustration}

The following sensitivity analyses examine the generality of our numerical findings in Sect. 3.2. We primarily shed light on the comparison between unconditional commitment and discretion because this comparison is analytically ambiguous, and because we believe this policy choice is the most relevant one in practice. 
Figures 4, 5 and 6 illustrate that the superiority of discretion in our basic setting is robust for reasonable ranges of the (expected) external benefit of clean power generation $\left(b_{1}, E\left[b_{2}\right]\right)$, the discount factor $(\delta)$ and exogenous technological progress (i.e., the share by which the cost parameter $c_{2}$ is below $c_{1}$ ). The impact of the policy cost $l$ on the welfare wedge between unconditional commitment and discretion merits a closer look. The bigger the policy cost, the larger is the policy-maker's incentive to deviate from the ex-ante optimal policy path under discretion-and the more preferable becomes commitment. Figure 7 illustrates, however, that for reasonable levels of the deadweight loss, i.e., for $l<1$, discretion outperforms commitment in our calibration. Yet, we also argue in Sect. 2 that $l$ may not only represent the marginal welfare cost of policy intervention in the narrower sense but additionally also other social overhead cost related to covering the expenditure for the subsidy. In this case, one can imagine $l>1$, and commitment outperforming discretion in terms of welfare.

\section{Welfare Analysis of Policy Scenarios with Uncertain External Benefits and Risk Aversion}

Welfare under discretion with uncertain external benefits and risk aversion is:

$$
\begin{aligned}
W^{A D *}= & W^{D *}+\frac{a l \delta}{2 c_{2}(1+2 l) n_{1}}\left((a l \delta-2(1+l) v(1+\delta))\left((1+4 l)(1+\delta)^{2}+l^{2}(4+\delta(8+5 \delta))\right)\right. \\
& -2 E[b] \delta(1+\delta)\left((1+2 l)^{2}+\delta(1+l(4+5 l))\right)-(1+2 l)^{2} \\
& \left.(1+\delta)^{2}\left(2 b_{1}+\frac{c_{1}}{c_{2}} \delta((1+\delta)(2 E[b]+2(1+l) v)-a l \delta)\right)\right)
\end{aligned}
$$

An economic interpretation of the problem would normally suggest that $W^{A D *}<W^{D *}$, i.e. the second term on the right hand side of Eq. (20) is negative: adding an extra cost (or costly risk) to firms' investments, in a situation where firms already under invest in the first place, should ceteris paribus reduce overall welfare. In the following, we show analytically that the difference indeed grows negative for an increasing risk aversion parameter $a$ when starting from $a=0$ (and thus from $W^{A D *}=W^{D *}$ ).

For very high levels of risk aversion $a$, however, the difference can, analytically, become zero and eventually even positive. This seems to happen for parameter sets for which the analytical model used does not anymore correspond to the described economic situation. This may especially be the case when, as an artifact of excessive risk costs, first and/or second period investments, $x_{1}$ or $x_{2 i}$, become negative so that a 'cost per (positive) investment unit' artificially becomes welfare positive in absolute levels in the model. While the related equations remain complex, below we show this in an analytically tractable way when simplifying the parameter space by imposing, for a few of the parameters, values (or ratios) assumed in the numerical illustration from Sect. 3.2.

To see that the second term on the right hand side of Eq. (20) is strictly negative for limited positive risk aversion factors $a$, we first note that it has exactly two roots: 


$$
\begin{aligned}
a_{1}= & \\
a_{2}= & 2(1+\delta)\left(b_{1} c_{2}(1+2 l)^{2}(1+\delta)+c_{1}(1+2 l)^{2}(E[b]+v+l v) \delta(1+\delta)^{2}\right. \\
& \left.+c_{2}\left((1+l)(1+2 l)^{2} v+(1+2 l)^{2}(E[b]+2(1+l) v) \delta+(1+l(4+5 l))(E[b]+v+l v) \delta^{2}\right)\right) / \\
& l \delta\left(c_{1}(1+2 l)^{2} \delta(1+\delta)^{2}+c_{2}\left((1+\delta)^{2}+4 l(1+\delta)^{2}+l^{2}(4+\delta(8+5 \delta))\right)\right),
\end{aligned}
$$

and that $a_{2}$ is strictly positive. In addition, $W^{A D *}-W^{D *}$ can be shown to have a single local extreme value, and to take a positive value for $a \rightarrow \infty$. Consequently, $W^{A D *}-W^{D *}<0$, i.e., welfare under discretion is lower with than without risk aversion, as long as $0=a_{1}<a<a_{2}$.

While details of the shape of $a_{2}$ are difficult to interpret, we can calculate the value of the investment levels that would result if the risk aversion parameter had the level $a_{2}$. For example, for $l=0.3, \delta=0.631$, and $\frac{c_{2}}{c_{1}}=\frac{0.0053}{0.0082}$, we find the strictly negative first-period investment level, $x_{1}=-\frac{0.006 b_{1}+1.008 E\left[b_{2} b_{1}\right]+1.318 v}{c_{1}}<0$. This would not make economic sense in our model, illustrating that analytically positive welfare impacts of risk aversion tend to occur for parameter sets that do not make full economic sense in our model.

\section{References}

Abrego L, Perroni C (2002) Investment subsidies and time-consistent environmental policy. Oxf Econ Pap 54:617-635

Aghion P, David PA, Foray D (2009) Science, technology and innovation for economic growth: linking policy research and practice in 'STIG systems'. Res Policy 38:681-693

Amacher GS, Malik AS (2002) Pollution taxes when firms choose technologies. South Econ J 68:891-906

Baldursson F, von der Fehr N-H (2008) Prices vs. quantities: public finance and the choice of regulatory instruments. Eur Econ Rev 52:1242-1255

Baumol WJ, Oates WE (1971) The use of standards and prices for protection of the environment. Swed J Econ 73:42-54

Biglaiser G, Horowitz JK, Quiggin J (1995) Dynamic pollution regulation. J Regul Econ 8:33-44

Browning EK (1987) On the marginal welfare cost of taxation. Am Econ Rev 77:11-23

Brunner S, Flachsland C, Marschinski R (2012) Credible commitment in carbon policy. Clim Policy $12: 255-271$

D’Amato A, Dijkstra BR (2015) Technology choice and environmental regulation under asymmetric information. Resour Energy Econ 41:224-247

Del Rio P, Mir-Artigues P (2014) A cautionary tale: Spain's solar PV investment bubble. Global Subsidies Initiative (GSI), International Institute for Sustainable Development (IISD), Geneva

Denholm P, Margolis R (2008) Supply curves for rooftop solar PV-generated electricity for the United States. Technical report NREL/TP-6A0-44073, National Renewable Energy Laboratory (NREL), Golden, $\mathrm{CO}$

Downing PB, White LJ (1986) Innovation in pollution control. J Environ Econ Manag 13:18-29

European Commission (2014) Communication from the commission to the European Parliament, the Council, the European Economic and Social Committee and the Committee of the regions: a policy framework for climate and energy in the period from 2020 to 2030. COM (2014) 15 final. European Commission, Brussels

European Commission (2018) Quarterly report on European electricity markets, vol 11 (issue 1; first quarter of 2018). European Commission, Brussels

Finon D, Perez Y (2007) The social efficiency of instruments of promotion of renewable energies: a transaction-cost perspective. Ecol Econ 62:77-92

Fisher S (1977) Long-term contracts, rational expectations, and the optimal money supply rule. J Polit Econ 85:191-206 
Fouquet D, Nysten JV (2015) Retroactive and retrospective changes and moratoria to RES support. Becker Büttner Held, Berlin

Foxon T, Pearson P (2008) Overcoming barriers to innovation and diffusion of cleaner technologies: some features of a sustainable innovation policy regime. J Clean Prod 16:S148-S161

Garnier E, Madlener R (2016) The influence of policy regime risks on investments in innovative energy technology. Energy J 37:145-160

Gawel E, Lehmann P (2019) Should renewable energy policy be 'renewable'? Oxf Rev Econ Pol $35: 218-243$

Greenstone M, Kopits E, Wolverton A (2013) Developing a social cost of carbon for US regulatory analysis: a methodology and interpretation. Rev Environ Econ Policy 7:23-46

Habermacher F, Lehmann P (2017) Commitment vs. discretion in climate and energy policy. CESifo working paper no. 6355, CESifo Group, Munich

Helm D, Hepburn C, Mash R (2003) Credible carbon policy. Oxf Rev Econ Pol 19:438-450

Helm D, Hepburn C, Mash R (2004) Time inconsistent environmental policy and optimal delegation. Discussion Paper 175, Department of Economics, Oxford University, Oxford, UK

Hepburn C (2006) Regulation by prices, quantities, or both: a review of instrument choice. Oxf Rev Econ Pol 22:226-247

Hintermann B, Peterson S, Rickels W (2016) Price and market behavior in phase II of the EU ETS: a review of the literature. Rev Environ Econ Policy 10:108-128

Hirth L (2013) The market value of variable renewables. Energ Econ 38:218-236

HM Revenue \& Customs (2014) Carbon price floor: reform and other technical amendments. HM Revenue \& Customs, London

Hoppmann J, Huenteler J, Girod B (2014) Compulsive policy-making - the evolution of the German feed-in tariff system for solar photovoltaic power. Res Policy 43:1422-1441

IEA (2017) $\mathrm{CO}_{2}$ emissions from fuel combustion. International Energy Agency (IEA), Paris

IRENA (2018) Renewable power generation costs in 2017. International Renewable Energy Agency (IRENA), Abu Dhabi

Jakob M, Brunner S (2014) Optimal commitment under uncertainty: adjustment rules for climate policy. Strateg Behav Environ 4:291-310

Kalkuhl M, Edenhofer O, Lessmann K (2013) Renewable energy subsidies: second-best policy or fatal aberration for mitigation? Resour Energy Econ 35:217-234

Karp L, Zhang J (2005) Regulation of stock externalities with correlated abatement costs. Environ Resource Econ 32:273-299

Kelly DL, Kolstad CD (1999) Bayesian learning, growth, and pollution. J Econ Anal Control 23:491-518

Kelly DL, Tan Z (2015) Learning and climate feedbacks: optimal climate insurance and fat tails. J Environ Econ Manag 72:98-122

Kennedy PW (1999) Learning about environmental damage: implications for emissions trading. Can J Econ 32:1313-1327

Kirchgässner G, Schneider F (2003) On the political economy of environmental policy. Public Choice 115:369-396

Kline D, Heimiller D, Cowlin S (2008) A GIS method for developing wind supply curves. Technical report NREL/TP-670-43053, National Renewable Energy Laboratory (NREL), Golden, CO

Krysiak FC (2011) Environmental regulation, technological diversity, and the dynamics of technological change. J Econ Dyn Control 35:528-544

Kydland F, Prescott E (1977) Rules rather than discretion: the inconsistency of optimal plans. J Polit Econ 85:473-492

Laffont JJ, Tirole J (1996) Pollution permits and environmental innovation. J Public Econ 62:127-140

Lohmann S (1992) The optimal degree of commitment: credibility versus flexibility. Am Econ Rev $82: 273-286$

Malik AS (1991) Permanent versus interim regulations: a game-theoretic analysis. J Environ Econ Manag 21:127-139

Marsiliani L, Renström TI (2000) Time inconsistency in environmental policy: tax earmarking as a commitment solution. Econ J 110:123-138

May N, Chiappinelli O (2018) Too good to be true? How time-inconsistent renewable energy policies can deter investments. DIW discussion papers 1726. German Institute for Economic Research (DIW), Berlin

Nemet GF, Jakob M, Steckel JC, Edenhofer O (2017) Addressing policy credibility problems for low-carbon investment. Glob Environ Change 42:47-57

Neuhoff K (2005) Large-scale deployment of renewables for electricity generation. Oxf Rev Econ Pol 21:88-110 
Palmer K, Burtraw D (2005) Cost-effectiveness of renewable electricity policies. Energ Econ 27:873-894

Perino G (2010) How delegation improves commitment. Econ Lett 106:137-139

Purkus A, Röder M, Gawel E, Thrän D, Thornley P (2015) Handling uncertainty in bioenergy policy design - a case study analysis of UK and German bioelectricity policy instruments. Biomass Bioenerg 79:64-79

REN21 (2016) Renewables 2016: global status report. Renewable energy policy network for the 21st century (REN21) Secretariat, Paris

Requate T (2005) Timing and commitment of environmental policy, adoption of new technology, and repercussions on R\&D. Environ Resour Econ 31:175-199

Requate T, Unold W (2001) On the incentives created by policy instruments to adopt advanced abatement technology if firms are asymmetric. J Inst Theor Econ 157:536-554

Requate T, Unold W (2003) Environmental policyincentives to adopt advanced abatement technology: will the true ranking please stand up? Eur Econ Rev 47:125-146

Rodrik D (2014) Green industrial policy. Oxf Rev Econ Pol 30:469-491

Roe GH, Baker MB (2007) Why is climate sensitivity so unpredictable? Science 318:629-632

Rogoff K (1985) The optimal degree of commitment to an intermediate monetary target. Quart J Econ 100:1169-1189

Rubin ES, Azevedo IML, Jaramillo P, Yeh S (2015) A review of learning rates for electricity supply technologies. Energy Policy 86:198-218

Schleich J, Walz R, Ragwitz M (2017) Effects of policies on patenting in wind-power technologies. Energy Policy 108:684-695

Strunz S, Gawel E, Lehmann P (2016) The political economy of renewable energy policies in Germany and the EU. Util Policy 42:33-41

Tarui N, Polasky S (2005) Environmental regulation with technology adoption, learning and strategic behavior. J Environ Econ Manag 50:447-467

Tol RSJ (2009) The economic effects of climate change. J Econ Perspect 23:29-51

Tol RSJ (2011) The social cost of carbon. Annu Rev Resour Econ 3:419-443

Ulph A, Ulph D (2013) Optimal climate change policies when governments cannot commit. Environ Resour Econ 56:161-176

Weitzman ML (1974) Prices vs. quantities. Rev Econ Stud 41:477-491

World Bank (2017) State and trends of carbon pricing 2017. World Bank, Washington

Yao DA (1988) Strategic responses to automobile emissions control: a game-theoretic analysis. J Environ Econ Manag 15:419-438

Ziegler L, Gonzalez E, Rubert T, Smolka U, Melero JL (2018) Lifetime extension of onshore wind turbines: a review covering Germany, Spain, Denmark, and the UK. Renew Sustain Energy Rev 82:1261-1271

Publisher's Note Springer Nature remains neutral with regard to jurisdictional claims in published maps and institutional affiliations. 